\title{
ELEIÇÕES, VOTO E INSTITUIÇÃO RELIGIOSA
}

\author{
Carlos Alberto Steil \\ Universidade Federal do Rio Grande do Sul
}

Os estudos antropológicos sobre política no Brasil, nos últimos anos, têm dado especial destaque para a análise e interpretação de eleições, num esforço de encontrar uma certa inteligibilidade para os votos que são depositados nas urnas em cada novo pleito. Publicações como as do Núcleo de Antropologia da Política vêm criando uma tradição quanto à temática e aos instrumentos metodológicos utilizados. Com uma abrangência nacional, o Núcleo não apenas tem produzido etnografias sobre eleições em diferentes regiões do país e em contextos institucionais diversos, mas também refletido teoricamente sobre estes estudos mais específicos ${ }^{1}$. São olhares, no entanto, que se posicionam desde o campo da política em sua relação com outras esferas da vida social. O trabalho de Ari Pedro Oro, se por um lado pode ser relacionado com esta literatura, com a qual mantém um diálogo, por outro revela-se portador de uma virtualidade nova na medida em que lança seu olhar sobre as eleições e o voto desde o campo religioso.

Neste sentido, encontramos no texto em pauta a convergência de duas vertentes de investigação: os estudos sobre o binômio religião e política, com uma longa tradição nas Ciências Sociais no Brasil, aos quais o autor se filia, e a contribuição recente da Antropologia da Política que, como se revela no texto, pode ser criativamente assimilada pela área da religião. Ao fazer esta articulação, Oro abre o caminho para uma revitalização do tema religião e política nas Ciências Sociais, apontando para aspectos específicos da lógica interna e do modelo institucional das diversas igrejas e grupos religiosos que incidem sobre o campo da política. Deste modo, alarga a possibilidade uma maior inteligibilidade dos votos que elegem "parlamentares religiosos".

${ }^{1}$ Para um conhecimento mais aprofundado da bibliografia produzida pelo Núcleo Antropologia da Política ver: Bezerra, 1999; Miranda, 1999; Palmeira e Goldman, 1996; Barreira, 1998; Barreira, 1998; Comerford, 1999. 


\section{Superando dicotomias: entre o objetivismo e o subjetivismo}

A ênfase na diferenciação interna do campo religioso permite ao autor romper tanto com uma perspectiva objetivista e homogeneizadora do agenciamento coletivo institucional do voto em candidatos identificados com certos grupos religiosos ou igrejas, quanto com uma perspectiva subjetivista que acentua os aspectos da identificação pessoal e das trajetórias individuais de candidatos e eleitores. As análises recentes sobre eleições realizadas pela Antropologia da Política, por exemplo, mesmo tendo incorporado uma preocupação com a superação desta dicotomia, através da introdução do conceito de subjetivação (Goldman, 1999), raramente levam em conta os aspectos relacionados com os formatos e os modelos institucionais das igrejas e grupos religiosos.

A perspectiva objetivista, como se sabe, esteve associada a idéia de uma ligação orgânica entre religião e política. As análises sociológicas de cunho marxista, que predominaram no Brasil até os anos 80, privilegiaram uma interpretação da religião em que os indivíduos desapareciam, subsumidos nas condições sociais e institucionais que estavam dadas. $\mathrm{O}$ foco estava posto na correlação de forças entre correntes progressistas e reacionárias e na divisão fundamental entre igrejas e grupos religiosos de direita ou de esquerda. Assim, deixavam de considerar a complexidade dos processos de escolhas políticas que se davam a partir da idiossincrasia dos seguidores e adeptos das igrejas e grupos religiosos particulares ${ }^{2}$.

A segunda perspectiva centrou-se no indivíduo como sujeito de suas opções religiosas, geralmente remetidas ao foro pessoal íntimo e associadas às religiões do "eu" (self), remetendo a um plano totalmente secundário os aspectos institucionais das diversas formas de estruturação da religião na sociedade contemporânea. Desde este ponto de vista, as "novas formas de crer", para usar uma expressão cara a $\mathrm{Oro}^{3}$, estariam

\footnotetext{
Devemos ter presente aqui a situação histórica e conjuntural do autoritarismo político dos anos 60 e 70 no Brasil onde estavam restringidos os direitos individuais, de modo que as escolhas pessoais estavam muito mais sujeitas às mediações institucionais.

${ }^{3}$ Refiro-mo aqui a um interessante artigo do autor publicado na revista REB intitulado "Modernas formas de crer" (Oro, 1997).
} 
fortalecendo de tal forma a dimensão racional das escolhas individuais, que estes passariam a agir de autônoma e livremente em todas as dimensões da vida social. A própria teoria da secularização, levada às suas últimas consequiências, acaba por conduzir a idéia de que as religiões não estariam mais influenciando na ordem da infra-estrutura, ou seja, do que efetivamente contaria para a organização e reprodução da sociedade. $\mathrm{Na}$ visão de Gauchet, possivelmente o pensador que produziu a mais completa e contundente síntese nesta direção, a secularização teria produzido, no final da longa démarche história da política no Ocidente, "uma sociedade atéia, habitada por crentes" (Gauchet, 1985; Steil, 1994).

O texto de Oro supera, a partir de uma exaustiva etnografia das eleições à Câmara de Vereadores da cidade de Porto Alegre, focada nos candidatos religiosos, esta dicotomia entre as perspectivas objetivistas e sobjetivistas. A percepção de que há um continuum entre a forma de organização e o modelo institucional adotado pela religião ou grupo religioso e o resultado das eleições, devolve à instituição um papel importante na definição dos votos de seus adeptos sem, contudo, desconsiderar o processo de subjetivação individual. Um processo que se torna possível através do deslocamento na análise de uma perspectiva mecânica da relação entre religião e voto para uma perspectiva mais sutil e mediatizada, onde a influência da religião sobre o voto de seus fiéis se torna possível na medida em aponta para uma homologia entre a ação religiosa e a ação política.

\section{O carisma e o ritual como chaves de interpretação do voto religioso}

Destaco dois elementos da argumentação de Oro que trazem uma contribuição original e de intensa força heurística para a interpretação do voto em candidatos religiosos. O primeiro diz respeito ao uso do conceito weberiano de carisma, ressaltando não a contraposição entre carisma e instituição, como aparece geralmente nas análises de corte mais objetivista, mas entre carisma pessoal e carisma institucional. $\mathrm{O}$ segundo refere-se à continuidade entre o político e o religioso que se realiza através do ritual, o qual se mostra ainda mais original e revela a 
percepção aguçada do etnógrafo em colocar-se em sintonia com os sentidos que seus "nativos" estão imprimindo em sua ação.

Assim, ao invés de pensar a tensão entre carisma pessoal e institucional como pólos opostos ou categorias de classificação das denominações religiosas, sua interpretação vai no sentido de destacar diferentes gradações que aproximam as igrejas e os grupos religiosos mais de um pólo ou de outro. De acordo com os dados apresentados por Oro, foram justamente as igrejas e os grupos religiosos detentores de um forte carisma institucional e que conseguiram acioná-lo no tempo quente da política, aqueles que alcançaram resultados mais positivos nas eleições de $2000 \mathrm{em}$ Porto Alegre ${ }^{4}$. Como se vê, não basta ser detentor de carisma institucional, mas é preciso acioná-lo no momento certo e num sentido estratégico.

Em relação ainda ao primeiro elemento, destaco o esforço do autor em chegar a um ponto comum capaz de transcender as fronteiras das igrejas e grupos religiosos particulares para compreender a relação entre voto e pertencimento religioso. Temos aqui uma análise que consegue, portanto, superar o senso comum de que "cada caso é um caso". Oro nos mostra que o sucesso da Igreja Universal do Reino de Deus nas eleições de 2000 em Porto Alegre em relação às conquistas das outras igrejas e grupos religiosos não se explica por particularidades ou especificidades exclusivas desta igreja, mas por uma virtualidade das instituições e grupos religiosos que pode ser encontrada em graus diversos em cada uma em particular. A diferença aqui não é de gênero, mas de grau. Se todas as igrejas e grupos religiosos detém um carisma institucional, algumas acionam mais e outras menos (ou nem acionam) este carisma por ocasião dos peitos eleitorais. E isto, segundo o autor, demarca diferenças significativas em relação ao resultado na contagem dos votos para os candidatos religiosos: os que se tornam depositários do carisma institucional têm mais chances do que os que correm por conta própria. Dito de outra forma, Oro nos faz perceber que, se o carisma institucional é um recurso à disposição de todas as igrejas e grupos religiosos, a maneira

\footnotetext{
${ }^{4}$ É importante salientar, para ser fiel à análise do autor, que algumas instituições religiosas, embora possuíssem um forte carisma institucional, como o caso da Igreja Católica, não o acionaram no momento das eleições.
} 
e a intensidade com que cada uma vai se apropriar dele depende de seus mitos de origem, de suas trajetórias históricas e da forma como elas vão se posicionar nas disputas dentro do campo religioso.

O segundo elemento que destacamos da análise o autor pode ser introduzido por uma citação do próprio texto em pauta. E, mesmo sendo repetitivo, peço licença ao leitor para citá-lo: "o ato de votar passa a ser concebido como um ato que preenche um sentido quase-religioso, na medida em que ele se torna uma espécie de exorcismo do demônio que se encontra na política...". E completa sua interpretação afirmando que "seus fiéis ( $d a$ IURD) assumem o ato de votar menos como um dever cívico e mais como um ritual religioso, no sentido de que o gesto de votar constitui-se no rechaço do mal que se apoderou da política e sua purificação pelo poder do bem que dela deverá se apoderar'. Esta continuidade entre o político e o religioso que se realiza através do ritual parece colocar em cheque as concepções de autonomia, ainda que relativa, das múltiplas esferas e campos de que se comporia a sociedade moderna. Não se trata, ao que parece, apenas de uma contaminação ou colonização do político pelo religioso, ou de fronteiras porosas onde se manifestam as heterodoxias religiosas, mas de um ato político (de cidadania) que é vivido e praticado como um ato sagrado e apreendido sub specie religiosa.

Poderíamos aqui trazer para o debate a abundante literatura sobre a “despolitização da política”, que denuncia o esvaziamento do seu conteúdo ideológico ${ }^{5}$; a perspectiva antropológica clássica da performance, que toma os eventos políticos como "dramas sociais"; ; teoria dos rituais, aplicada ao campo da política como um recurso para interpretar conflitos étnicos ${ }^{7}$; ou, ainda, as análises que buscam compreender os atos políticos como rituais numa relação estreita e direta com os ritos religiosos ${ }^{8}$. No entanto, visto

\footnotetext{
Literatura sobre o tema da despolitização é bastante extensa, mas à guisa de exemplo cito alguns autores que se tornaram clássicos: Sennett, 1988; Perrineau, 1994; Baumann, 2000.

${ }^{6}$ Entre os clássicos que trabalham a partir desta perspectiva poderíamos citar: Turner, 1974; Turner, 1987; Geertz, 1991.

${ }^{7}$ Em relação a esta forma de abordar a questão política remeto o leitor para os textos seguintes: Tambiah, 1997; Steil, 1998.

${ }^{8}$ Neste sentido é clássico o texto de Kertzer, 1988.
} 
que este artigo tem um caráter de comentário sobre o texto principal, apresentado como objeto de debate, nos limitaremos a lançar a hipótese de que a citação destacada acima levanta uma questão nova que pode ser iluminada por estas teorias referidas. Um trabalho mais aprofundado se faz necessário, no entanto, para que se possa superar zonas de sombra que se mantém quando se trata de situar a religião no quadro da modernidade, no qual a esfera do político se apresenta necessariamente como secular e autônoma em relação ao sagrado.

Observamos hoje, na sociedade contemporânea, uma tendência a mesclar esferas sociais que numa perspectiva sociológica clássica eram vistas como totalidades unificadas e bem delimitadas. De modo que vemos éticas, valores e visões de mundo sendo deslocadas de um campo para outro. A análise weberiana, pedra fundamental da teoria da secularização nas Ciências Sociais, que se apresenta como um instrumento valioso para os estudos da religião na sociedade moderna, precisa ser reatualizada para dar conta da interpretação da religião nas sociedades pós-modernas. A polarização entre religião e ciência ou, mais especificamente, entre fé e política, que durante anos serviu para demarcar competências e hierarquizar ações na sociedade, parece perder sua força diante de contextos, como o analisado por Oro, em que o religioso emerge no político e o político no religioso.

Ao apropriar-se do ritual político do voto como um ritual religioso de exorcismo, os adeptos da IURD não estão apenas contaminando o campo da política com o religioso, mas usando, pragmaticamente, um ato político, sem deslocá-lo do campo da política, como um ritual religioso de caráter mágico. Não se trata, portanto, simplesmente de transferir o capital simbólico acumulado de um campo para o outro, no sentido atribuído por Bourdieu (1987), mas do uso mágico de mediações e rituais políticos para fins religiosos ou mágicos, destituindo-os de seu significado ético e ideológico. De modo que, mais uma vez, reaparece a relação entre religião e magia na comparação entre práticas e discursos de diferentes igrejas e grupos religiosos ${ }^{9}$.

\footnotetext{
Convém trazer aqui os comentários de Birman sobre a associação entre política e magia no contexto brasileiro. A autora mostra em seu texto sobre a IURD e os meio de comunicação a propósito do episódio do" chute da imagem de Nossa Senhora Aparecida" por um bispo da Universal (1995) que esta associação está marcada por uma ambigüidade cultivada pelos atores políticos com objetivos de classificação e hierarquização dos grupos sociais (Birman, 1996).
} 
A comparação entre os sentidos atribuídos ao voto pelo fiel da IURD e aqueles de que se revestem as escolhas dos cristãos de esquerda, particularmente das CEBs, nas eleições aponta para duas formas extremas no campo religioso brasileiro de lidar com o político. Estas realidades empíricas nos remetem a dois "tipos ideais", no sentido weberiano, que estabelecem um divisor de águas no campo religioso: a imanência e a transcendência. Desde este ponto de vista, poderíamos situar a IURD no campo das religiões que enfatizam a imanência, enquanto os cristãos de esquerda, identificados pela sua adesão à Teologia da Libertação, poderiam ser situados no pólo das religiões da transcendência.

Como mostra a etnografia de Oro, os fiéis da IURD estabelecem uma relação direta e imediata entre a política e a religião, o que nos remete à imanência do sagrado no mundo. Um sagrado que, no caso específico da política, se expressa principalmente na sua forma negativa: o mal ou o demônio que penetra as suas entranhas e que precisa ser exorcizado pela ação ritual. É esta ausência de separação entre a ordem natural e sobrenatural que permite transformar ritos políticos em atos religiosos. Neste mesmo sentido, Oro interpreta o milenarismo presente na concepção religiosa da IURD, o qual promete a felicidade não para o além ou para o futuro, mas para aqui e agora. Uma felicidade que será alcançada pela mediação dos recursos presentes neste mundo e não por uma transfiguração ou transposição para uma ordem sobrenatural.

\section{Mediações políticas da opção religiosa}

No pólo oposto dessa concepção imanentista está uma perspectiva religiosa que não só respeita a autonomia da esfera política, mas também estabelece uma divisão fundamental entre a ordem natural e a ordem sobrenatural. Pensada a partir da teoria da secularização, a ação política se inscreve dentro de uma esfera que se institui como um sistema de crenças (reconhecimento) e valores (ética) que se legitima a partir de princípios e relações que se definem no seu próprio campo (Bourdieu, 1989:187-189). Instituindo-se fora de qualquer fundamento sagrado, a 
política estabelece uma relação de exterioridade com o religioso, remetendo-o a sua esfera específica, onde são produzidas convicções e motivações psicológicas que podem a vir determinar opções políticas. Estas, no entanto, quando se expressam no campo específico da política, devem transubstanciar-se em atos de natureza política.

A ação política dos cristãos secularizados depende, portanto, de uma adesão prévia ao sistema de crenças e valores políticos. Assim, aos cristãos que adentram o campo da política é pedido que se submetam a um longo processo de iniciação às regras do jogo político. E, aos que apenas exercitam seu direito ao voto, que façam suas escolhas em consonância com essas mesmas regras estabelecidas no campo da política. Entre a adesão religiosa e a ação política se estabelece uma série de mediações de ordem racional e ética que acaba destituindo o religioso de um sentido prático no campo da política ${ }^{10}$. Rituais políticos devem ser executados e vividos como atos de cidadania e rituais religiosos como atos de fé e de culto.

Essa divisão, no entanto, tem se apresentado empiricamente muito mais como uma ideologia, do que como uma prática efetiva. Seria interessante trazer aqui a sugestão de Otávio Velho de que poderíamos estar confundindo, a partir desta perspectiva secularizante, a redução de uma presença estrutural da religião na sociedade moderna com o "fim" da religião. Neste sentido, ele chama atenção para um "duplo e imbricado movimento pelo qual a religião, por um lado reduz sua presença estrutural, e, por outro, amplia a sua presença performática..." (Velho, 1996). Esta presença performática se expressa tanto através da presença da religião na política quanto da política na religião, mantendo sempre, no entanto, as especificidades destes campos. De forma que, qualquer ponto de contato que divisamos nesta relação entre política e religião precisa ser pensado a partir de múltiplas mediações para dar conta da sua complexidade.

${ }^{10}$ Possivelmente caberia aqui uma reflexão sobre o posicionamento crítico de Milbank em seu polêmico livro "Teologia e Teoria" Social em que busca demonstrar o caráter questionável dos pressupostos que alicerçam a teoria social secular (Milbank, 1995). 


\section{Voto e magia}

Ao destituir o voto de sua conotação racional política, atribuindolhe uma função mágica, a IURD e as demais igrejas e grupos religiosos (ou mesmo setores conservadores no âmbito da Igreja Católica) que assumem esta postura, posicionam-se do lado da fé em oposição à razão. Emerge, assim, no "tempo da política", a clássica controvérsia entre magia e religião. Deste modo, a ação ritual do voto que exorciza o mal e o demônio da política confere aos fiéis uma positividade que não encontramos naqueles que inscrevem o exercício do voto no campo da racionalidade política. Crer no poder de Deus de intervir diretamente na realidade social através do milagre torna-se a base para a construção de uma solidariedade e de uma identidade positiva dos crentes, enquanto depositários de valores morais calcados na Bíblia, que estão sendo negados pelas elites intelectualizadas do país e particularmente pelos religiosos que argumentam a favor de uma fé racional.

Se os votos dos crentes têm esta conotação positiva e mágica, os candidatos que são seus destinatários se tornam instrumentos da ação divina. Estes, por sua vez, se fortalecem, como mostram os dados levantados por Oro, na medida em que suas candidaturas vêm respaldadas por suas instituições de origem. Nesta perspectiva, a mediação dos partidos políticos, no seu sentido clássico, se torna, de certo modo, dispensável, visto que a investidura que consagra o candidato a uma eleição não é conferida pela agremiação partidária, mas pela instituição religiosa. Caberia, neste ponto, fazer o caminho inverso daquele trilhado por Bourdieu no seu texto clássico sobre a representação política, no capítulo VII do Poder simbólico (Bourdieu, 1989), em que o autor busca no sagrado a gênese do político. Ou seja, não se trata aqui de explicar a emergência da autonomia do político a partir de um longo processo de dessacralização, mas de tentar compreender a ressacralização de instituições políticas, pensadas como instâncias seculares e racionais.

Por outro lado, não se trata simplesmente de um retorno do sagrado, no sentido de uma retomada das funções que a religião 
desempenhou na sociedade antes do advento da modernidade, mas de uma redefinição destas funções, num contexto de hegemonia do pensamento racional secularizado. Noutras palavras, os candidatos que trazem a investidura de suas igrejas não são apenas portadores de um "capital político" investido neles pela instituição como retorno pelos seus serviços prestados à instituição (Bourdieu, 1989). São, ao que tudo indica, portadores de uma investidura que lhes é conferida por graça e escolha divinas, independente de suas obras ou méritos.

A contabilidade proposta por Bourdieu entre investimento pessoal e retorno institucional, que pode ser válida para os partidos políticos, parece não se aplicar imediatamente às igrejas, mesmo quando estas agem como se fossem partidos, apresentando seus candidatos oficiais e estabelecendo acordos, alianças e compromissos no campo político. Neste aspecto a lógica institucional da igreja se confronta com a lógica dos partidos. O capital de função, para usar uma expressão de Bourdieu, que é transferido pelo partido para o candidato é diferente daquele que é conferido pela igreja ao seu candidato oficial. Decorre desta contradição, possivelmente, a dificuldade das igrejas em apresentar candidatos oficiais através de partidos que se organizem como agremiações político-ideológicas, mantendo um forte aparato de controle sobre seus candidatos ${ }^{11}$.

Aos candidatos religiosos dificilmente se poderá pedir um alto investimento no partido, uma vez que seu prestígio em última instância não depende deste, mas de suas instituições religiosas. De modo que, aos políticos dos partidos que existem enquanto tal, como afirma Bourdieu, não há a possibilidade de negarem a sua filiação partidária sem negarem a si mesmos, visto que estão investidos do seu carisma institucional. Aos políticos religiosos a filiação partidária se apresenta menos decisiva para sua carreira, visto que o carisma institucional com que eles contam não lhes advém propriamente do partido mas da instituição religiosa. Assim, os políticos religiosos vão disputar pouco o

${ }^{11}$ Estamos nos referindo aqui a partidos que existem como organizações permanentes orientadas para a conquista do poder e que propõem aos seus militantes e aos seus eleitores não só uma doutrina, mas também um programa de pensamento e de ação, exigindo por isso uma adesão global e antecipada (Bourdieu, 1989: 167). 
poder sobre o aparelho partidário ou mesmo se profissionalizar enquanto políticos que vivem para a política.

Queremos crer que esta possibilidade dos candidatos religiosos de virem a acionar o carisma institucional de suas igrejas, dispensando a investidura do partido, explicaria, ao menos em parte, a ausência, apresentada nos dados levantados por Oro, de candidatos religiosos nos partidos de esquerda. Ou seja, nossa hipótese é que se trata mais de uma incompatibilidade ou inadequação de ordem prática do que ideológica. Dificilmente o político teria condições de investir simultaneamente e com a intensidade que é requerida na instituição religiosa e no partido de modo a garantir uma dupla investidura. Em suma, é especialmente esta situação que leva os candidatos religiosos a buscar partidos sem forte conotação ideológica, que se organizam mais como siglas ou agremiações que viabilizam candidaturas avulsas.

É evidente que toda esta reflexão parte do pressuposto de que se é verdade que o carisma institucional vem sempre associado ao carisma pessoal, também é preciso ter em conta que esta associação se revela com diferentes intensidades. De modo que podemos nos deparar freqüientemente com situações em que o carisma ou a notoriedade pessoal se sobrepõe ao carisma da instituição religiosa ou do partido. No entanto, os casos trazidos por Oro referem-se basicamente a candidatos que dependem de suas instituições religiosas para poderem ser guindados aos cargos políticos que as eleições conferem.

Por fim, somos levados a crer que as relações entre religião e política na sociedade contemporânea não podem ser pensadas fora das transformações que vêm ocorrendo na maneira mesma como a religião se apresenta hoje. Como vimos, assistimos a uma profunda redefinição das funções e do próprio conceito de religião. Uma mudança que aponta fundamentalmente para uma presença mais performática da religião na sociedade do que estrutural ou orgânica. Por outro lado, esta tendência à performance não encontramos apenas na religião, mas também na política. O que torna a relação entre política e religião muito mais ajustada. 


\section{Referências bibliográficas}

BARREIRA, C. Crimes por encomenda. Violência e pistolagem no cenário brasileiro. Rio de Janeiro, Relume Dumará, 1998. (Coleção Antropologia da Política, 3).

BARREIRA, I. Chuva de papéis. Ritos e símbolos de campanhas eleitorais no Brasil. Rio de Janeiro, Relume Dumará, 1998. (Antropologia da Política, 2).

BAUMANN, Z. Em busca da política. Rio de Janeiro, Jorge Zahar Editor, 2000.

BEZERRA, M. O. Em nome das "bases": política, favor e dependência pessoal. Rio de Janeiro, Relume Dumará, 1999. (Coleção Antropologia da Política; 3).

BIRMAN, P. "O bispo, o povo e a TV: alguns efeitos, talvez inesperados, da presença política recente dos pentecostais". Cadernos de Conjuntura/IUPERJ, v., n. 54, p. 5-13, 1996.

BOURDIEU, P. O Poder Simbólico. Lisboa, Rio de Janeiro, Bertrand Brasil, 1989. (Memória e Sociedade).

COMERFORD, J. C. Fazendo a luta: sociabilidade, falas e rituais na construção de organizações camponesas. Rio de Janeiro, Relume Dumará, 1999. (Antropologia da Política, 5).

GAUCHET, M. Le désenchantement du monde. Une histoire politique de la religion. Paris, Gallimard, 1985.

GEERTZ, C. Negara. O Estado teatro no século XIX. Lisboa, DIFEL, 1991. (Memória e sociedade).

GOLDMAN, M. Alguma antropologia. Rio de Janeiro, Relume Dumará, 1999. (Antropologia da Política, 6).

KERTZER, D. Ritual, politics and power. New Haven and London, Yale University Press, 1988. 
MILBANK, J. Teologia e teoria social. São Paulo, Loyola, 1995.

MIRANDA, J. Carisma, sociedade e política: novas linguagens do religioso e do político. Rio de Janeiro, Relume-Dumará, 1999. (Coleção Antropologia da Política; 6).

ORO, A. P. "Modernas formas de crer". Revista Eclesiástica Brasileira, v. 36, n. 141, p. 313-328, 1997.

PALMEIRA, M. G. S. \& GOLDMAN, M. (org.). Antropologia, voto e representação política. Rio de Janeiro, Contra Capa, 1996.

PERRINEAU, P. L'engagement politique. Déclin ou mutation? Paris, Presses de la Fondation Nationale des Sciences Politiques, 1994.

SENNETT, R. O declínio do homem público. São Paulo, Companhia das Letras, 1988.

STEIL, C. A. "Para ler Gauchet". Religião e Sociedade, v. 16, n. 3, p. 24-49, 1994.

STEIL, C. A. "Catolicismo popular tradicional e ação pastoral. Desafios e perspectivas no contexto da cultura contemporânea". Teocomunicação, v. 28, n. 119, p. 87-104, 1998.

TAMBIAH, S. J. "Conflito etnonacionalista e violência coletiva no sul da Ásia". Revista Brasileira de Ciências Sociais, v. 12, n. 34, p. 5-24, 1997.

TURNER, V. W. Dramas, Fields and Metaphors: Simbolic action in human society. Ithaca/London, Cornell University Press, 1974. (Simbol, Mith and Ritual series).

TURNER, V. W. The Antropology of Performance. New York, PAJ Publications, 1987.

VELHO, O. G. "Religião e política". Cadernos de Conjuntura/IUPERJ, v., n. 54, p. 1-4, 1996. 